\title{
STUDY OF ANTIMICROBIAL ACTIVITY OF SILVER-DOPED HYDROXYAPATITE
}

\author{
HIBU WAHID, ANJUVAN SINGH* \\ Department of Biotechnology, School of Bioengineering and Biosciences, Lovely Professional University, Phagwara, Punjab, \\ India. Email: anjuvan@gmail.com
}

Received: 17 June 2019; Revised and Accepted: 02 July 2019

ABSTRACT

Objective: Hydroxyapatite (Hap) is an important material used for implants because of its structural similarity with calcium phosphate of the teeth and bones. Hap is mostly used in the situations where load-bearing implants are needed, such as in dental and orthopedic applications. Dental plaque is caused due to the bacteria which induces secondary caries through microleakage between the restoration and the tooth structure.

Methods: An attempt has been made to provide materials with antibacterial activity by incorporating an antibacterial agent into the chemical mixture (Hap). This study delineates the process of synthesizing silver-doped $\mathrm{Hap}\left(\mathrm{Ca}_{10} \mathrm{Ag}_{\mathrm{x}}\left(\mathrm{PO}_{4}\right)_{6}(\mathrm{OH})_{2}\right)$ by wet chemical precipitation method and by varying the silver concentration $(0.3 \%-0.5 \%)$. The synthesized silver-doped Hap was further characterized using Fourier transform infrared spectroscopy and X-ray diffraction (XRD) analysis. The antimicrobial activities were tested against Gram-negative bacteria Escherichia coli.

Results: The maximum zone of inhibition against Escherichia coli was observed when equal concentration of Hydroxyapatite and Silver were mixed together i.e $\mathrm{X}_{\mathrm{Ag}}=0.5 \%$ Zone of inhibition helps to determine the antimicrobial activity of silver-doped Hap. An increase in the zone of inhibition indicates the least growth of microorganisms which was observed at a silver concentration $\mathrm{X}_{\mathrm{Ag}}=0.5 \%$.

Conclusions: Silver-doped Hap was synthesized successfully using the chemical precipitation method and was characterized using Fourier transform infrared spectroscopy and XRD analysis. It can be concluded that silver-doped Hap can be an excellent substitute material used as dental implant device.

Keywords: Hydroxyapatite, Antibacterial activity, Bioactivity, Biocompatibility.

(C) 2019 The Authors. Published by Innovare Academic Sciences Pvt Ltd. This is an open access article under the CC BY license (http://creativecommons. org/licenses/by/4. 0/) DOI: http://dx.doi.org/10.22159/ajpcr.2019.v12i8.34603

\section{INTRODUCTION}

During the past few decades, the development of biomedical engineering has significantly contributed to different fields of research, particularly biomaterial and has improved on the characteristic features of biomedical devices, thereby allowing their commercial use. Hydroxyapatite (Hap), also called hydroxylapatite, is one of the most extensively studied biomaterials due to its excellent biocompatibility, bioactivity, and osteoconductivity [1]. It is a bioceramic material that belongs to the family of apatites, having general formulae $\left(\mathrm{Ca}_{10}\left[\mathrm{PO}_{4}\right]_{6}[\mathrm{OH}]_{2}\right)$. Due to its chemical composition being similar to that of the bones and teeth, it is widely used in medical applications such as implants, coatings, and prostheses [2-4]

However, in recent years, the major concern regarding the health problem has been the development of resistance to antimicrobial agents by pathogenic bacteria. Therefore, in recent years, incorporation of certain antimicrobial agents $(\mathrm{Ag}+, \mathrm{Cu} 2+$ and $\mathrm{Zn} 2+)$ into the implant material has been suggested. Silver-containing materials, in particular, have been found to have a broad spectrum of antimicrobial properties and have received much attention. Their studies revealed that the silver release has a significant effect on the antibacterial efficiency [5].

Although the exact mechanism of antibacterial activity shown by silver ions is not yet understood, it is currently used to control bacterial growth in various applications such as dentistry and catheters. [6,7]. Different studies have shown that these ions have the ability to penetrate into the materials cell wall that causes DNA to transform into a condensed form. Further, these ions bind to the functional groups of proteins causing their denaturation [8]. Therefore, silver-doped ceramics have shown high antimicrobial activity and also chemical durability. The objective of this research work is to synthesize silver-doped bioceramic material so that we can evaluate the in vitro antimicrobial activity against Escherichia coli.

\section{METHODS}

\section{Synthesis of silver-doped Hap}

The synthesis of silver-doped Hap was done using the chemical precipitation method [9]. An appropriate amount of $\left(\mathrm{Ca}\left[\mathrm{NO}_{3}\right]_{2} \cdot 4 \mathrm{H}_{2} \mathrm{O}\right)$ $(0.25 \mathrm{~mol} / \mathrm{L})$ was dissolved in $150 \mathrm{ml}$ of distilled water, and similarly, $\mathrm{AgNO}_{3}(0.01 \mathrm{~mol} / \mathrm{L})$ was dissolved in $150 \mathrm{ml}$ of distilled water in separate beakers. The two resulting solutions of calcium nitrate and silver nitrate were mixed together in a $500 \mathrm{ml}$ beaker and stirrer continuously with magnetic stirrer for about $30 \mathrm{~min}$. About $0.24 \mathrm{~mol} / \mathrm{L}$ of diammonium hydrogen phosphate $\left(\left[\mathrm{NH}_{4}\right] 2 \mathrm{HPO}_{4}\right)$ were taken in another beaker and dissolved in $300 \mathrm{ml}$ of distilled water.The solution of diammonium hydrogen phosphate was added drop wise to a solution of beaker containing two mixture solution of calcium and silver nitrate solution, and resulting solution was heated up to $80^{\circ} \mathrm{C}$ on hot plate with continuous stirring by magnetic stirrer. For the variation of concentration of silver in silver-doped Hap, the synthesis of Hap was carried out with different concentration of silver as $\mathrm{X}_{\mathrm{Ag}}=0.3, \mathrm{X}_{\mathrm{Ag}}=0.4$, and $\mathrm{X}_{\mathrm{Ag}}=0.5$. The $\mathrm{pH}$ of the solution was maintained as 10.0 throughout the reaction with the help of ammonium hydroxide solution [1].

The resulting solution was allowed to stand undisturbed for the deposited mixtures to settle down and then washed 3-4 times with distilled water. The filtrate obtained was dried in an oven at $80^{\circ} \mathrm{C}$ for $24 \mathrm{~h}$. The dried material was ground to obtain a fine powder of silver-doped Hap. The dried precipitate was processed to get fine powder with the help of mortar and pestle. HAp/Ag complexes were characterized using X-ray diffraction (XRD) and Fourier transform infrared spectroscopy (FT-IR) techniques. The powder was then given the shape of tablets.

\section{Characterization of silver-doped Hap}

Different techniques are used to characterize silver-doped Hap. Here, we have discussed some of the important techniques and their 
principles that we have used to characterize silver-doped Hap in this project work. The techniques are FTIR and XRD.

\section{FTIR analysis}

FTIR is a sensitive technique which is used to identify organic and inorganic chemicals by checking the chemical bonds in a molecule by producing an infrared absorption spectrum. In this method, the infrared rays pass through the sample. Some of those IR are absorbed by the sample and some transmitted. No two unique molecular structures produce the same infrared spectrum. The functional groups present in the prepared powder were identified by FT-IR. For this, 1\% of the powder were mixed and ground with $99 \% \mathrm{KBr}$. Pallet size of $10 \mathrm{~mm}$ diameter for FT-IR measurements was prepared by pressing the powder mixture at a load of 5 tons for $2 \mathrm{~min}$, and the spectrum was taken in the range of $400-4000 \mathrm{~cm}^{-1}$.

\section{XRD analysis}

XRD is currently a standard technique for the study of crystal structures and atomic spacing. The XRD measurements for the silver-doped Hap samples were recorded using a diffractometer with nickel-filtered $\mathrm{CuK} \alpha$ $(\lambda=1.5418 \AA)$ radiation. The diffraction patterns were collected in the $2 \theta$ range of $0-90$, with a step of 0.02

\section{Microbial strain}

Microbial strain of $E$. coli was used to test the antimicrobial activity of silver-doped Hap.

\section{Disc diffusion test}

Disc diffusion is a common method to check the antibacterial activity of Hap with silver and without silver (control) evaluated against E. coli using the disc diffusion technique [10]. A disc diffusion test is performed to test whether the particular bacteria are susceptible to certain chemical or not. According to the diameter, a zone of inhibition of culture growth the microorganism can be observed sensitive or resistant. The experiments were performed in triplicates for each concentration of silver made in such a way that it contains nine plates containing solidified media and was incubated at $37^{\circ} \mathrm{C}$ for $24 \mathrm{~h}$. The inhibition of bacterial growth was studied by measuring the zones formed around the tablets ( $\mathrm{cms}$ ).

\section{RESULTS AND DISCUSSION}

\section{Synthesis of Hap}

Silver-doped Hap was synthesized using chemical precipitation method as shown in Fig. 1. Although the preparation is simple, it requires a great care to make stable Hap. One of the most important parameters for synthesis is $\mathrm{pH}$ which was maintained at 10 throughout the reaction. Temperature too plays an important role which was maintained at $100^{\circ} \mathrm{C}$.

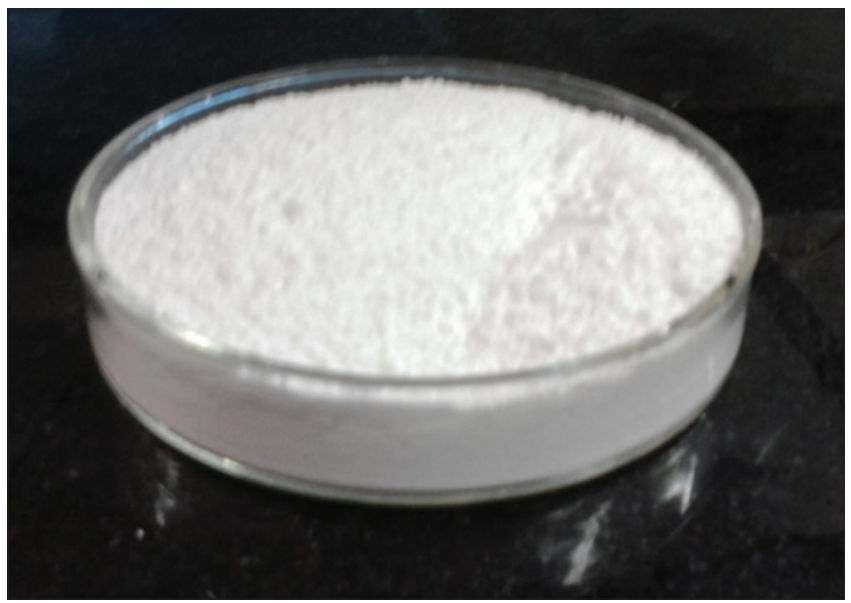

Fig. 1: Silver-doped hydroxyapatite in powder form
Formation of Hap powder to pallet

Fig. 2 shows the formation of pallet of silver-doped Hap. The samples were dried in a hot air at $100^{\circ} \mathrm{C}$ for $48 \mathrm{~h}$, and then, they were crushed in mortar and pestle. Silver-doped Hap tablets were prepared using the dye punch machine. The concentration of silver varies so as to check antimicrobial activity of silver-doped Hap against Gram-negative bacteria, E. coli by disc diffusion test at different concentrations, i.e., XAg-0.3, XAg-0.4, and XAg-0.5.

\section{FT-IR spectroscopy analysis}

To identify the functional groups present in the prepared Ag HAp powder by wet chemical precipitation method, FT-IR was done in Fig. 3. The results obtained clearly represent the presence of different vibrational modes that correspond to hydroxyl groups and phosphates. The spectrum can be divided into four main regions with the peaks having wave numbers as $3500 \mathrm{~cm}^{-1}, 1400 \mathrm{~cm}^{-1}, 1100 \mathrm{~cm}^{-1}$, and $600 \mathrm{~cm}^{-1}$. The presence of strong $\mathrm{OH}^{-}$peak could be observed from the spectrum. The peak which is observed at $3425 \mathrm{~cm}^{-1}$ is because of the presence of $-\mathrm{OH}$ bond [11]. This peak is due to $\mathrm{O}-\mathrm{H}$ stretching vibrations in Hap. The bands that are observed at $1600-1700 \mathrm{~cm}^{-1}$ and $3200-33600 \mathrm{~cm}^{-1}$ are due to $\mathrm{H}-\mathrm{O}-\mathrm{H}$ bands of water lattice [12]. Bands corresponding to phosphate and hydrogen phosphate groups observed in the spectrum include $565.16 \mathrm{~cm}^{-1}, 603.74 \mathrm{~cm}^{-1}, 632.67 \mathrm{~cm}^{-1}, 962.51 \mathrm{~cm}^{-1}$, and $1000-1100 \mathrm{~cm}^{-1}$ for the $\mathrm{PO}_{4}{ }^{3-}$ groups [12]. and at $875.71 \mathrm{~cm}^{-1}$ for the $\mathrm{HPO}_{4}{ }^{2-}$ ions [13]. Thus, from IR studies, the presence of $\mathrm{PO}_{4}{ }^{3-}$ group is confirmed.

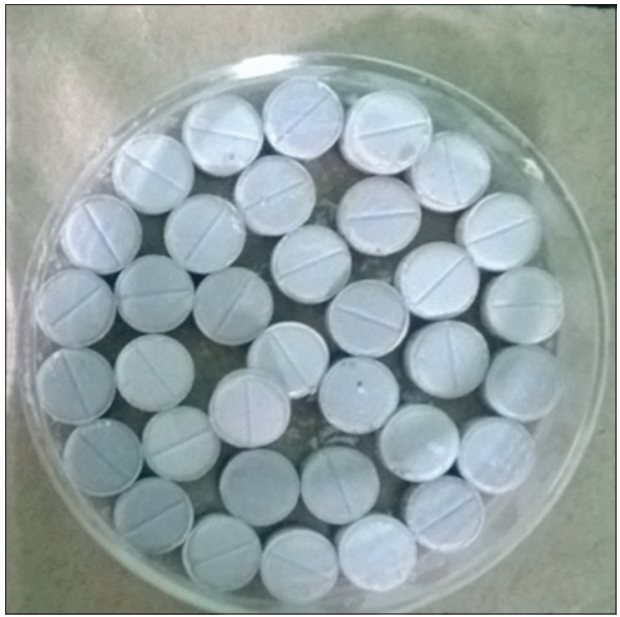

Fig. 2: Silver-doped hydroxyapatite pallet

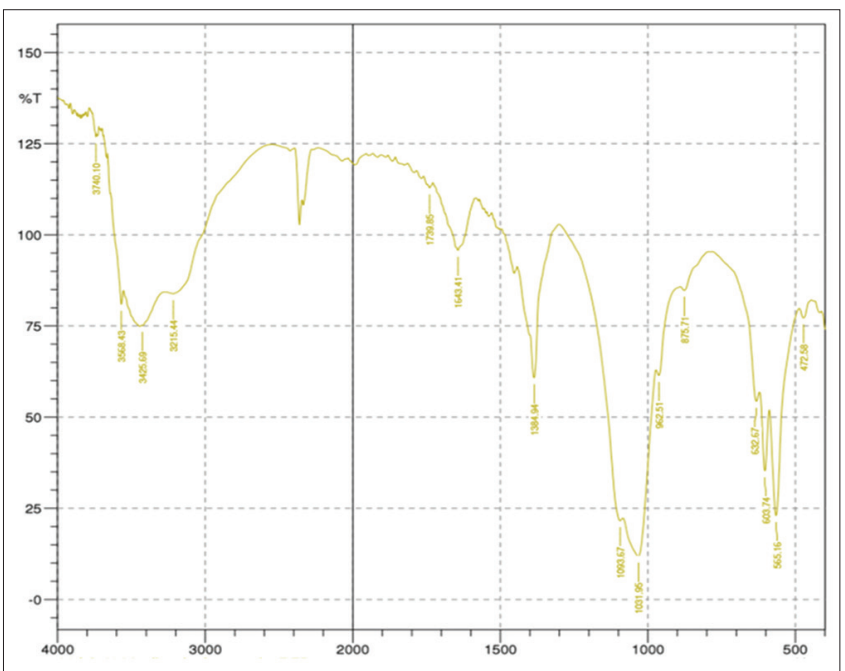

Fig. 3: Fourier transform infrared spectroscopy spectra from silver-doped hydroxyapatite 


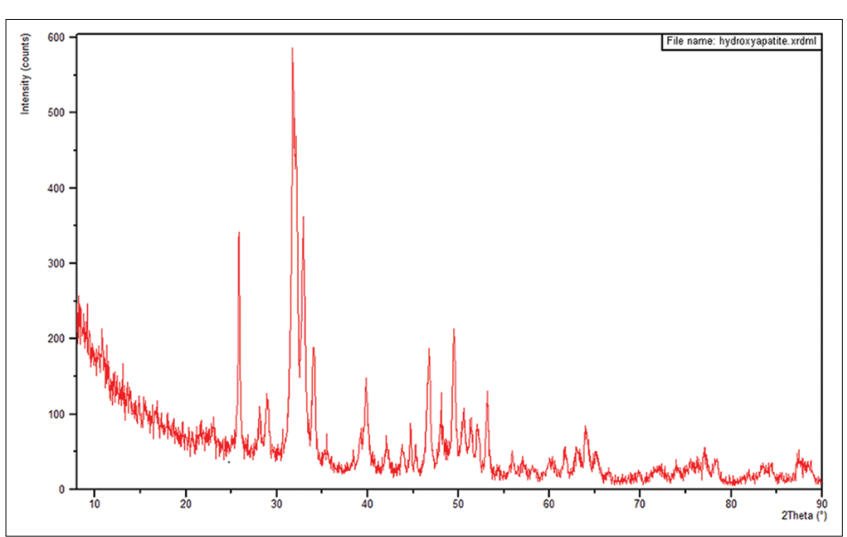

Fig. 4: X-ray diffraction spectra of synthesized silver-doped hydroxyapatite

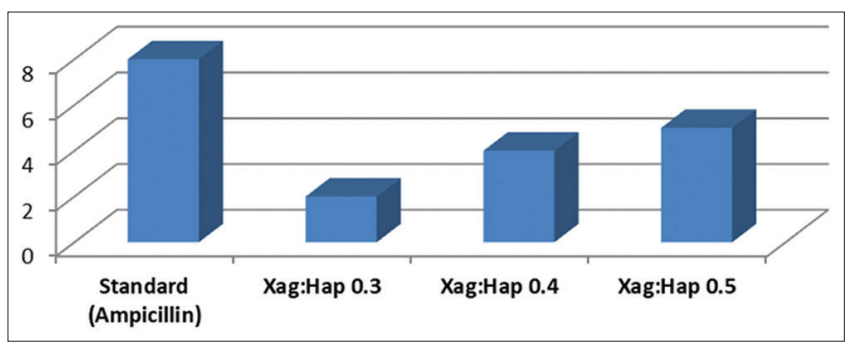

Fig. 5: Graphic representation of the measurement of zone of inhibition at different concentration of silver-doped Hap against Escherichia coli

\section{XRD spectroscopy}

XRD spectra of silver Hap show distinct diffraction patterns in Fig. 4. The maximum intensity of the peak was obtained at $2 \theta=31.7684$. The peak analysis matched very closely to the standard obtained from JCPDS File No-090432 [14].

Synthesis of silver-doped Hap using different concentrations of silver

Different concentrations of silver $\mathrm{x}=0.3,0.4$, and 0.5 were taken to synthesize silver-doped Hap. The precipitates formed by the procedure mentioned above in methodology were later used to check the antimicrobial activity of Hap with different concentrations of silver against $E$. coli.

\section{Antibacterial activity test}

Antibacterial test was done by measuring the zone of inhibition for the plates incubated with $E$. coli at different concentrations of silver-doped Hap using silver concentrations at silver $\mathrm{x}=0.3,0.4$, and 0.5 which is shown in Fig. 5.

From Fig. 5, it is clear that XAg:Hap $=0.5$ showed good inhibition against $E$. coli. The zone of inhibition for $\mathrm{X}_{\mathrm{Ag}}=0.3$ was $2.00 \pm 0.025 \mathrm{~mm}$, $X_{\mathrm{Ag}}=0.4$ was $4.00 \pm 0.012 \mathrm{~mm}$, and $X_{\mathrm{Ag}}=0.5$ was $5.00 \pm 0.016 \mathrm{~mm}$. These values were compared with amoxicillin (standard). It can be clearly understood that as the concentration of silver in Hap was increased, the zone of inhibition increases because of the effect of silver particles on the growth of bacteria. The silver particles present in petri-plate binds to the membrane protein of the bacteria cell and results in causing death to the bacterial cell [15]. In case of $E$. coli, the effective concentration of silver was found at $\mathrm{X}_{\mathrm{Ag}}: \mathrm{Hap}=0.5$.

\section{CONCLUSIONS}

Silver-doped Hap was synthesized successfully using the chemical precipitation method and was characterized using FTIR and XRD analysis. The synthesized powder was pure white and crystalline in nature. The present study shows effect of bacterial growth on increasing concentrations of silver-doped Hap. In our study, effective concentration of silver was found at $\mathrm{X}_{\mathrm{Ag}}=0.5$. Hence, it can be concluded that the proper concentration of silver required to inhibit the growth of bacteria in still to be explored at the high range of concentration of silver. It may be further modified or manipulated to synthesize silverdoped Hap at their optimum range of concentration of silver so that it can be substituted as dental implant device. The dental implant device may serve as antibacterial property and inhibit the growth of bacteria.

\section{ACKNOWLEDGMENT}

The authors are grateful to the authorities of the Department of Biotechnology, School of Bioengineering and Biosciences, Lovely professional University, Punjab, India, for the facilities.

\section{AUTHORS' CONTRIBUTION}

Guidance for the work, data interpretation and corrections, and editing of the manuscript were done by corresponding author Anjuvan Singh. Synthesis of silver-doped Hap, consideration of synthesis process parameters, characterization of synthesized material, and writing of the manuscript were done by the first author, Hibu Wahid.

\section{CONFLICTS OF INTEREST}

The authors declare no conflict of interest.

\section{REFERENCES}

1. Ciobanu CS, Iconaru SL, Chifiriuc MC, Costescu A, Le Coustumer P, Predoi D. Synthesis and antimicrobial activity of silverdoped hydroxyapatite nanoparticles. Biomed Res Int 2013;2013:916218.

2. Xin R, Leng Y, Chen J, Zhang Q. A comparative study of calcium phosphate formation on bioceramics in vitro and in vivo. Biomaterials 2005:26:6477-86.

3. Rámila A, Vallet-Regí M. Static and dynamic in vitro study of a sol-gel glass bioactivity. Biomaterials 2001;22:2301-6.

4. Ragel CV, Vallet-Regi M, Rodriguez-Lorenzo LM. Preparation and in vitro bioactivity of hydroxyapatite/solgel glass biphasic material. Biomaterials 2002;23:1865-72.

5. Poca L, Dubnika A, Loca D, Berzina-Cimdina L. Bioactivity of silver doped hydroxyapatite scaffolds in simulated body fluids. Key Eng Mater 2014;604:175-9.

6. Catauro M, Raucci MG, De Gaetano F, Marotta A. Antibacterial and bioactive silver-containing na2O $\times$ caO $\times 2 \mathrm{SiO} 2$ glass prepared by sol-gel method. J Mater Sci Mater Med 2004;15:831-7.

7. Crabtree JH, Burchette RJ, Siddiqi RA, Huen IT, Hadnott LL, Fishman A, et al. The efficacy of silver-ion implanted catheters in reducing peritoneal dialysis-related infections. Perit Dial Int 2003;23:368-74.

8. Dakal TC, Kumar A, Majumdar RS, Yadav V. Mechanistic basis of antimicrobial actions of silver nanoparticles. Front Microbiol 2016;7:1831.

9. Singh A. Hydroxyapatite, a biomaterial: Its chemical synthesis, characterization and study of biocompatibility prepared from shell of garden snail, Helix aspersa. Bull Mater Sci 2012;35:1031-8.

10. Revathi M, Letticia M, Malathy D. Microwavsynthesis of silver nanoparticles by polyol method and testing their synergistics antibacterial activity in the presence of vancomycin. Asian J Pharm Clin Res 2018;11:288-93.

11. Russell SW, Luptak KA, Carlos TA, Alford TL, Pizziconi V. Chemical and structural evolution of sol-gel-derived hydroxyapatite thin films under rapid thermal processing. J Am Ceram Soc 1996;79:837-43.

12. Ciobanu CS, Massuyeau F, Constantin LV, Predoi D. Structural and physical properties of antibacterial ag-doped nano-hydroxyapatite synthesized at 100 C. Nanoscale Res Lett 2011;6:613.

13. Doat A, Pelle F, Gardant N, Lebugle A. Synthesis of luminescent bioapatite nanoparticles for utilization as a biological probe. J Solid State Chem 2004;177:1179-87.

14. Rasool I, Singh A. In vitro studies of biomate ial device hydroxyapatite prepared from different routes for biomedical applications. Asian J Pharm Clin Res 2018;11:493-7.

15. Jung WK, Koo HC, Kim KW, Shin S, Kim SH, Park YH, et al. Antibacterial activity and mechanism of action of the silver ion in Staphylococcus aureus and Escherichia coli. Appl Environ Microbiol 2008;74:2171-8. 